\title{
Do not blame bats and pangolins! Global consequences for wildlife conservation after the SARS-CoV-2 pandemic
}

\author{
Manfredo A. Turcios-Casco ${ }^{1,2} \cdot$ Roberto Cazzolla Gatti ${ }^{2,3}$
}

Received: 18 May 2020/Revised: 17 August 2020 / Accepted: 14 September 2020 /

Published online: 19 September 2020

(C) Springer Nature B.V. 2020

\begin{abstract}
This pandemic situation requests a correct understanding of our impacts on wildlife conservation, which would also provide benefits for our species. In this commentary we revised and discussed some of the repercussions that SARS-CoV-2 pandemic may have to wildlife. We propose four actions that should be taken into account to protect and conserve wildlife in this pandemic era: wildlife "wet" markets must close; human interference with wildlife must be reduced; bats and pangolins must be conserved and not blamed; and Chinese traditional medicine must be more controlled.
\end{abstract}

Keywords Bats $\cdot$ Biodiversity conservation $\cdot$ COVID-19 $\cdot$ Pandemic $\cdot$ Pangolins

\section{Introduction}

While the SARS-CoV-2 outbreak was expanding in a pandemic, many research groups tried to rapidly identify its likely origin and initially pointed to bats (Chiroptera). Some studies suggested that bats, because of their unique behavior (Fan et al. 2019), are the most probable natural host of the new coronavirus and, via an unknown intermediate, they infected humans (Guo et al. 2020). Although some authors have suggested that the origin of this new coronavirus could be a Chinese lab (Xiao and Xiao 2020), new evidence has focused on the recombination of SARS-CoV-2 by a potential spillover from bats to Sunda pangolins (Manis javanica), that have a weak immune system and can be easily attacked by new pathogens (Cazzolla Gatti 2020a). In fact, although some scientific evidence is still needed to support this hypothesis, it is likely for pangolin coronavirus to have originated

Communicated by Dirk Sven Schmeller.

Manfredo A. Turcios-Casco and Roberto Cazzolla Gatti have contributed equally to this work.

Roberto Cazzolla Gatti

robertocgatti@gmail.com

1 Departamento de Vida Silvestre, Instituto Nacional de Conservación y Desarrollo Forestal, Áreas Protegidas y Vida Silvestre (ICF), Francisco Morazán, Honduras

2 Biological Institute, Tomsk State University (TSU), Tomsk, Russia

3 Konrad Lorenz Institute for Evolution and Cognition Research, Klosterneuburg, Austria 
from bat viruses as a result of illegal trapping of alive animals in East Asia and their sale in the wildlife market of Wuhan, in the Hubei province of China, with a subsequent humanto-human transmission (Andersen et al. 2020; Lau et al. 2020). However, the animal species that is at the origin of SARS-CoV-19 has yet to be identified (Cyranoski 2020). Nonetheless, this is not a new situation. Other viruses, such as the SARS-CoV, the MERS$\mathrm{CoV}$ and the Indian Nipah virus (Hu et al. 2015), are responsible for zoonoses and epidemics transmitted by infected reservoir animals to human beings. Animals host pathogens that in normal conditions are rarely transmitted to our species. However, the abuses perpetrated on the environment at a global scale (i.e. wildlife poaching and trade, deforestation, wildfires, climate change, overfishing, etc.) increase the likelihood of interspecies transmission (Cazzolla Gatti 2020b).

\section{A new threat for bats and pangolins}

The identification of the possible origin and hosts of this new coronavirus has seemingly fostered ancestral fear towards bats from the public opinion and even their worldwide mass culling or eradication was claimed (Zhao 2020). While scientists try to track back the evolutionary road of the new coronavirus, threats to bats have increased. For example, in China people have started requesting that hibernating bats in or near their houses be expelled and, in some cases, bats were captured and released into the wild in unsuitable habitats (Zhao 2020). This is why, since this pandemic started, we have been concerned about the repercussions that misconceptions on these species could have on wildlife and, particularly, on bat and pangolin conservation efforts.

When we see what happens in the streets where the market takes place in Wuhan, where customers walk through animal waste and blood, it is not hard to understand how deadly viruses can easily pass from one species to another. There is ample occasion for spillover due to the mixture of dogs, cats, snakes, raccoons, genets, chickens, pigs, bats, pangolins, fish of all types and sizes. Indifferent, but not oblivious, buyers stroll in front of piles of tiny cages where animals wait for hours, often for days, for their death sentence.

This is the fate, for instance, of the Malayan pangolin (Manis javanica), a critically endangered species according to the International Union for Conservation of Nature (IUCN) (Challender et al. 2019). The Malayan pangolin is illegally trapped in Malaysia and Indonesia, in those forests where trees are logged to produce tropical timber, paper and palm oil (Cazzolla Gatti et al. 2019; Cazzolla Gatti and Velichevskaya 2020). Then, pangolins are sold in Chinese wet markets like the one in Wuhan because, with thousands of other critically endangered animals and plants, they are thought to be essential elements of traditional Chinese medicine (Cazzolla Gatti 2020a). The scales of this mysterious and rare animal are extracted through boiling the bodies that are then dried, which is considered helpful for breastfeeding, preventing infections and treating epidermal problems. Considering the absence of any scientific basis for these practices, it seems even more regrettable to justify the extermination of any species on Earth.

Similarly, Rhinolophus species, a bat genus supposedly responsible for previous epidemic viruses, are captured in China and sold in wet markets because their dried body parts are added to wines or to powders to detoxicate the body (Wassenaar and Zou 2020). Moreover, in some regions of Asia, many people continue to eat bat's flesh because it is considered a delicacy, and in China it is believed to have medicinal qualities (Humane Society International 2019).

Bats are affected by climate change (the extreme temperatures, in particular) and deforestations for intensive agriculture. For instance, forest logging may force bats to feed 
on insects whose life cycle is disrupted by climate change and by the use of pesticides (Stechert et al. 2014). Moreover, the increased proximity of farms to caves, once surrounded by natural forests, increases the chances for bats to interact with livestock (Calisher et al. 2006).

\section{Four urgent actions to conserve wildlife and prevent next pandemics}

Here we propose four urgent actions that should be taken into account in order to reduce the risk of future pandemics and, at the same time, protect wildlife:

1. Wildlife "wet" markets must close. The unhygienic, mixed-species markets that sell alive and dead animals, often captured illegally from their natural habitats, and that are linked to most of the recent zoonotic epidemics (Humane Society International 2020) must close after the enactment of international agreements.

2. Human interference with wildlife must be reduced. Any impact that our species has on wildlife (e.g. deforestation, overfishing, habitat degradation, pollution, etc.) must be halted. The interactions between researchers (particularly in biogenetics labs), biologists, and conservationists must also be based only on ethical and professional principles and must avoid interference with natural processes and wildlife.

3. Bats and pangolins must be conserved and not blamed. There are more than 1,400 bat species in all continents excluding Antarctica and most of them participate in diverse ecological processes and ecosystem services from pollination to seed dispersal, from pest control to ocean and land fertilization at many ecological levels (Kunz et al. 2011; Bat Conservational International 2020). Moreover, as the second most diverse extant mammal group, bats have faced many human-related problems that influence their populational trends (e.g. extermination with fire set into their caves, demonization related to witchcraft and superstitions, and more important nowadays, consideration as harmful mammals due to their relations with diseases). Similarly, pangolins are an endangered group of only 8 species that live in Asia and Sub-Saharan Africa. They are nocturnal and solitary animals in nature, they meet conspecifics only to mate and live in hollow trees or ground borrows (Maurice et al. 2019). Therefore, their chances to get in contact with bats and become an intermediate host of pathogens is unlikely in nature. However, pangolins are captured and forced to survive in small cages in wet markets, surrounded by alive and dead bats. Under such conditions, due to the weak immune system of pangolins, an infection becomes very likely (Cazzolla Gatti 2020a). Moreover, pangolins have very few offspring during their life and are the most smuggled mammal and one of the most endangered animal in the world (Challender et al. 2014; Challender and Waterman 2017). Due to their unique eco-physiological characteristics, both bats and pangolins are very sensitive to temperature variations, and climate change can increase the pressures on their populations (Cazzolla Gatti 2020a). Therefore, we must stop threatening their survival by halting poaching and taking serious action to reduce deforestation, forest degradation, and climatic changes.

4. Chinese traditional medicine must be controlled. Although Chinese traditional medicine dates back to more than 5000 years, there is an urgency to regulate it beyond any cultural preconception or discrimination. Many animal products are included in recommended treatments and the use of wildlife in these medications has had a huge impact on their conservation status (Mainka and Mills 1995). Although the demand for wildlife in the Chinese traditional medicine has occurred for thousands of years, the recent human population growth (there are currently 1.400 billion people in 
China) and the higher average income have had a catastrophic effect on nature. Moreover, for almost all species employed in the Chinese traditional medicine, the areas from which they are taken to supply these practices belong to underdeveloped or developing countries where environmental regulations and controls are scarce. We acknowledge that a sudden shift (for instance towards the use of cultivated plants as substitutes) of traditional medicine practices and the radical abandon of animal use for millions of people would be unlikely and unrealistic. However, in this pandemic era, international agencies must increase the protection of species in their habitats, enforce legislation and control of local and international wildlife trade. Sanctions, including political and economic strong actions (which are needed to protect the planet and not only the interests of developed countries), should be started if Chinese authorities will not effectively patrol and punish the exploitation of wildlife and endangered species.

The implementation of new, more stringent international laws and the increase of public environmental awareness will be to the benefit of these species and will reduce future risks of zoonotic diseases. Alternative sources of income for the areas where wildlife is threatened such as the transfer of sustainable know-how from developed countries for the development of ecotourism and conservation activities, can also reduce environmental pressures at its source. Protecting wildlife will also mean protecting ourselves.

Acknowledgements We are grateful to Esther Carmen (Department of Environment and Geography, University of York, UK and Konrad Lorenz Institute for Evolution and Cognition Research, Klosterneuburg, Austria) for her help and suggestions in revising our manuscript.

\section{Compliance with ethical standards}

Conflict of interest The authors declare no conflict of interest.

\section{References}

Andersen KG, Rambaut A, Lipkin WI, Holmes EC, Garry RF (2020) The proximal origin of SARS-CoV-2. Nat Med 26:450-452

Bat Conservational International (2020) BCI's FAQ on Bats and Covid-19. https://www.batcon.org/pdfs/ BCI_FAQ_Bats_Covid_English.pdf Accessed 20 April 2020.

Calisher CH, Childs JE, Field HE, Holmes KV, Schountz T (2006) Bats: important reservoir hosts of emerging viruses. Clin Microbiol Rev 19:531-545

Cazzolla Gatti R (2020a) The pangolin's revenge: SARS-CoV-2 did not emerge from a lab but from wildlife exploitation. GAIA 29:79-82

Cazzolla Gatti R (2020b) Coronavirus outbreak is a symptom of Gaia's sickness. Ecol Model 426:109075

Cazzolla Gatti R, Velichevskaya A (2020) Certified "sustainable" palm oil took the place of endangered Bornean and Sumatran large mammals habitat and tropical forests in the last 30 years. Sci Total Environ 742:140712

Cazzolla Gatti R, Liang J, Velichevskaya A, Zhou M (2019) Sustainable palm oil may not be so sustainable. Sci Total Environ 652:48-51

Challender D, Waterman C (2017) Implementation of CITES Decisions 17.239 B) and 17.240 on Pangolins (Manis spp.). Prepared by IUCN for the CITES Secretariat

Challender DW, Waterman C, Baillie JE (2014) Scaling up pangolin conservation. Zoological Society of London, London, IUCN SSC Pangolin Specialist Group Conservation Action Plan

Challender D, Willcox DHA, Panjang E, Lim N, Nash H, Heinrich S, Chong J (2019) Manis javanica. https://doi.org/10.2305/IUCN.UK.20193.RLTS.T12763A123584856.en Accessed 20 April 2020. 
Cyranoski D (2020) Mystery deepens over animal source of coronavirus. Pangolins are a prime suspect, but a slew of genetic analyses has yet to find conclusive proof. Nature 579:18-19

Fan Y, Zhao K, Shi ZL, Zhou P (2019) Bat coronaviruses in China. Viruses 11:1-14

Guo YR, Cao QD, Hong ZH, Tan YY, Chen SD, Jin HJ, Tan KS, Wang DY, Yan Y (2020) The origin, transmission and clinical therapies on coronavirus disease 2019 (COVID-19) outbreak: an update on the status. Mil Med 7:1-10

Hu B, Ge X, Wang LF, Shi Z (2015) Bat origin of human coronaviruses. Virol J 12:1-10

Humane Society International (2019) Wildlife markets and COVID-19.https://www.hsi.org/wp-content/ uploads/2020/04/Wildlife-Markets-and-COVID-19-White-Paper-FINAL-6-Apr-2020.pdf Accessed 20 April 2020.

Kunz T, Braun de Torrez E, Dana B, Lobova T, Fleming TH (2011) Ecosystem services provided by bats. Ann N Y Acad Sci 1223:1-38

Lau SKP, Luk HKH, Wong ACP, Li KSM, Zhu L, He Z, Fung J, Chan TTY, Fung KSC, Woo PCY (2020) Possible bat origin of severe acute respiratory syndrome coronavirus 2. Emerg Infec Dis. https://doi. org/10.3201/eid2607.200092

Mainka SA, Mills JA (1995) Wildlife and traditional Chinese medicine: supply and demand for wildlife species. J Zoo Wildl Med 26:193-200

Maurice ME, Ebong EI, Fuashi NA, Godwill I, Zeh AF (2019) The ecological impact on the distribution of pangolins in Deng-Deng National Park, Eastern Region Cameroon. Global J Ecol. https://doi.org/10. 17352/gje.000009

Stechert C, Kolb M, Bahadir M, Djossa BA, Fahr J (2014) Insecticide residues in bats along a land usegradient dominated by cotton cultivation in northern Benin, West Africa. Environ Sci Pollut R 21:8812-8821

Wassenaar TM, Zou Y (2020) 2019_nCoV/SARS-CoV-2: rapid classification of betacoronaviruses and identification of Traditional Chinese Medicine as potential origin of zoonotic coronaviruses. Lett Appl Microbiol 70:342-348

Xiao B, Xiao L (2020) The possible origins of 2019-nCoV coronavirus. Preprint https://doi.org/10.13140/ RG.2.2.21799.29601 Accessed 28 March 2020

Zhao H (2020) COVID-19 drives new threat to bats in China. Science 367:1436

Publisher's Note Springer Nature remains neutral with regard to jurisdictional claims in published maps and institutional affiliations. 